\title{
Co-infección viral respiratoria en niños hospitalizados por infección respiratoria aguda y su impacto en la gravedad clínica
}

\author{
Pamela Martínez, Jaime Cordero, Cristián Valverde, Nancy Unanue, \\ Roberto Dalmazzo, Paula Piemonte, Ivonne Vergara y Juan P. Torres
}

\section{Viral respiratory co-infections in pediatric patients admitted for acute respiratory infection and their impact on clinical severity}

Introduction: Respiratory viruses are the leading cause of acute respiratory tract infection (ARI) in children. It has been reported that viral respiratory co-infection could be associated with severe clinical course. Objectives: To describe the frequency of viral co-infection in children admitted for ARI and evaluate whether this co-infection was associated with more severe clinical course. Patients and Methods: Prospective, descriptive study in pediatric patients who were hospitalized for ARI, with molecular detection of at least 1 respiratory virus in nasopharyngeal sample studied by PCR-Microarray for 17 respiratory viruses. Results: 110 out of 147 patients with detection of $\geq 1$ respiratory virus were included. Viral co-infection was detected in 41/110 (37\%). 22/110 children (20\%) were classified as moderate to severe clinical course and 88/110 (80\%) were classified as mild clinical course. In the group of moderate to severe clinical course, viral respiratory co-infection was detected in 6/22 (27.3\%), compared to $35 / 88(39.8 \%)$ in the mild clinical course group. No statistically significant difference was found regarding the presence of co-infection between groups $(\mathrm{p}=0.33)$. Conclusions: We detected high rates of viral co-infection in children with ARI. It was not possible to demonstrate that viral co-infections were related with severe clinical course in hospitalized children.

Key words: Viral respiratory infection, acute respiratory infection, severity, viral co-infection.

Palabras clave: Infección respiratoria viral, infección respiratoria aguda, gravedad, co-infección viral.

\section{Introducción}

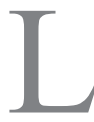

os virus respiratorios son la principal causa de infección respiratoria aguda (IRA) en pediatría ${ }^{1,2}$. Los virus más frecuentemente detectados por métodos diagnósticos convencionales son: virus respiratorio sincicial (VRS), virus influenza, virus parainfluenza y adenovirus $(\mathrm{ADV})^{3}$. Se ha descrito IRA en niños, causada por más de un virus respiratorio, en especial en casos de IRA baja ${ }^{4-7}$. Sin embargo, la co-infección viral ha sido poco caracterizada, probablemente debido a que los métodos diagnósticos convencionales han sido poco sensibles en la detección de co-infecciones ${ }^{8}$. Con el desarrollo de la reacción de polimerasa en cadena (RPC) para detectar virus respiratorios se ha podido mejorar el diagnóstico de patógenos respiratorios en $85^{1-5}$ a $93 \%{ }^{9}$, permitiendo además la búsqueda simultánea de varios virus respiratorios en una misma reacción ${ }^{1-10}$.

Se ha descrito que aquellos pacientes pediátricos con co-infección viral requerirían más días de hospitalización y presentarían infecciones respiratorias de curso más grave $^{2-6-11-12}$. No obstante, la información respecto a la im- portancia de la co-infección de virus respiratorios en niños es escasa. Van der Zalm y cols. ${ }^{5}$, compararon la detección de patógenos respiratorios entre niños sintomáticos y asintomáticos concluyendo que los casos sintomáticos ocurren más frecuentemente en niños más pequeños (bajo 2 años de edad) y en aquellos con más de un patógeno respiratorio detectado. Cilia y cols. ${ }^{8}$, describieron que aquellos pacientes que cursan IRA con co-infección viral presentan mayor gravedad en su evolución. Sin embargo, existen estudios que no demuestran relación entre co-infección viral y gravedad de la evolución de IRA en niños ${ }^{13}$. En nuestro país se ha descrito hasta $16 \%$ de co-infección viral en IRA en niños ${ }^{14}$ y Täger y cols., la han reportado en niños inmunocomprometidos que han cursado con IRA alta o baja ${ }^{15}$. Por otra parte, en Chile se ha comunicado poca experiencia respecto al impacto de la co-infección viral en la gravedad del cuadro clínico. Palomino y cols., utilizando inmunofluorescencia y aislamiento viral concluyeron que la infecciones concominantes causadas por VRS y ADV no tienen un curso clínico más grave que las causadas por ADV como virus único ${ }^{16}$.

El objetivo de este trabajo fue describir la frecuencia
Clínica Las Condes, Santiago, Chile.

Centro de Pacientes Críticos Pediátricos (PM, JC, CV, RD) Departamento de Pediatría ((NU JPT).

Laboratorio Biología Molecular (PP, IV).

Financiamiento: no hubo. Conflictos de interés: no se declaran.

Recibido: 27 de septiembre de 2011

Aceptado: 2 de febrero de 2012

Correspondencia a: J. Pablo Torres Torretti jptorres@clc.cl 
de co-infección viral en niños hospitalizados por IRA y determinar si esta co-infección se relacionó con una evolución clínica más grave.

\section{Pacientes y Métodos}

Se realizó un estudio descriptivo y prospectivo, en pacientes pediátricos hospitalizados por una IRA en el Departamento de Pediatría y el Centro de Pacientes Críticos Pediátricos de Clínica Las Condes, Santiago, Chile, entre junio y agosto de 2010.

Se incluyeron todos los pacientes bajo 18 años de edad, internados por IRA y que tuvieron detección molecular de al menos un virus respiratorio. Se excluyeron los pacientes portadores de enfermedades crónicas cardiacas, neurológicas o musculares e inmunosupresión. No se excluyeron los pacientes con patología crónica respiratoria (asma, hiper-reactividad bronquial, síndrome bronquial obstructivo a repetición). El estudio fue aprobado por el Comité de Ética institucional.

Una vez ingresado el paciente, se le tomó una muestra por aspirado nasofaríngeo a la cual se le realizó extracción automatizada de ácidos nucleicos (MagNA Pure ${ }^{\circledR}$ Compact, Roche, Suiza) y posteriormente detección de 17 virus respiratorios (influenza A, B y C, parainfluenza 1, 2, 3, 4a y 4b, VRS A y B, rinovirus, adenovirus, echovirus, bocavirus, coronavirus, metapneumovirus A y B) a través de una plataforma de RPC-microarreglos (CLART Pneumovir ${ }^{\circledR}$, Genómica, España), de acuerdo a las instrucciones del fabricante ${ }^{17-19}$. Esta técnica se basa en una amplificación inicial con transcriptasa reversa para los virus ARN y posteriormente una hibridación por complementariedad de bases con varias sondas representativas de cada uno de los 17 virus en un microarreglo.

Se registraron datos bio-demográficos (edad, sexo, antecedentes mórbidos generales y familiares), características clínicas (signos, síntomas, diagnóstico de egreso, días de hospitalización, requerimientos de oxígeno y/o de apoyo ventilatorio), descripción de la radiografía de tórax y el resultado del estudio molecular de virus respiratorios.

Definiciones: Se definió como IRA al conjunto de infecciones del tracto respiratorio causadas por microorganismos virales o bacterianos, con menos de 15 días de evolución, y que presentó uno o más de los siguientes síntomas o signos clínicos: tos, rinorrea, odinofagia, otalgia, disfonía, dificultad respiratoria, fiebre. Se definió como IRA alta y baja a la patología que afectó a las vías respiratorias en la región proximal o distal a la laringe, respectivamente, según criterios clínicos y radiológicos. A partir de los datos clínicos, se agrupó a los pacientes de acuerdo a la detección de un virus respiratorio o de co-infección respiratoria viral y según evolución clínica. Se definió como co-infección viral a la detección de más de un virus respiratorio en la muestra de aspirado nasofaríngeo de cada paciente. En el grupo de evolución clínica moderada a grave (MG) se incluyeron aquellos pacientes que requirieron una $\mathrm{FIO}_{2} \geq 0,5$ y/o apoyo ventilatorio invasor o no invasor, y en el grupo de evolución clínica leve $(\mathrm{L})$ a aquellos pacientes que requirieron una $\mathrm{FIO}_{2}<$ $0,5 \sin$ asistencia ventilatoria.

\section{Análisis estadístico}

Para evaluar la asociación entre variables categóricas se utilizó el test de $\chi^{2}$ con ajuste de Yates y regresiones logísticas. Las diferencias entre grupos se evaluaron con pruebas t student para las medias (dada la distribución normal de las variables) y test de Levene para varianzas. Todas las pruebas fueron de dos colas y se consideró estadísticamente significativo un valor de $\mathrm{P}$ de 0,05 . Para el análisis estadístico, se utilizó el programa SPSS Statistics versión 17.0.

\section{Resultados}

De un total de 394 niños hospitalizados por IRA, en 147 se realizó estudio molecular de virus respiratorios, resultando positivo para al menos un virus en 119/147 pacientes $(80,9 \%)$ de los cuales 110 cumplieron con los criterios de inclusión del estudio.

El promedio de edad fue de 31,1 meses y 57/110 (52\%) eran de sexo femenino. En un total de 110 pacientes se detectó al menos un virus respiratorio, de los cuales $41 / 110(37 \%)$ de los casos tuvieron co-infección viral, incluyendo 4/41 $(3,6 \%)$ pacientes con detección de tres virus respiratorios (Tabla 1). El virus detectado con mayor frecuencia fue el VRS 87/110 (79\%), seguido de bocavirus $19 / 110(20,9 \%)$ y virus influenza B 17/110 (18,7\%). Las co-infecciones virales más frecuentes fueron VRS y bocavirus (10/41, 24,3\%), VRS y metapneumovirus (9/41, $21,9 \%$ ) y VRS e influenza B $(8 / 41,19,5 \%)$ (Tabla 2$)$. En relación a la evolución clínica, 22/110 niños (20\%) correspondieron al grupo con evolución MG y 88/110 (80\%) correspondieron al grupo con evolución L. El diagnóstico de egreso más frecuente fue IRA baja (80/110; 72,7\%).

No hubo diferencias significativas al comparar el grupo de pacientes con co-infección respiratoria viral y los niños con infección respiratoria viral única respecto a los días de oxigenoterapia, días de hospitalización, IRA baja, antecedentes mórbidos, síntomas de ingreso y evolución clínica MG o L (Tabla 3).

Al comparar los pacientes según gravedad (MG versus L) se observó una diferencia significativa respecto a los días de oxigenoterapia (8,57 días versus 2,55 días, $\mathrm{p}<0,05)$, días de hospitalización (9,5 días versus 4,6 días, $\mathrm{p}<0,05)$, detección de VRS $(22 / 22,100 \%$ en MG versus $65 / 88,74 \%$ en $\mathrm{L}, \mathrm{p}<0,05)$ y dificultad respiratoria 
Tabla 1. Características bio-demográficas y clínicas de 110 niños hospitalizados por infección

respiratoria aguda. Santiago, junio-agosto 2010

\begin{tabular}{|c|c|c|}
\hline & $\mathrm{n}$ & $\%$ \\
\hline \multicolumn{3}{|l|}{ Sexo } \\
\hline Masculino & 53 & $(48,2)$ \\
\hline \multicolumn{3}{|l|}{ Edad } \\
\hline Edad promedio en meses (DE) & \multicolumn{2}{|c|}{$31,1(40,3)$} \\
\hline \multicolumn{3}{|l|}{ Distribución según edad } \\
\hline$<12$ meses & \multicolumn{2}{|c|}{37} \\
\hline 13-23 meses & \multicolumn{2}{|c|}{29} \\
\hline 2-5 años & \multicolumn{2}{|c|}{29} \\
\hline$>5$ años & \multicolumn{2}{|c|}{15} \\
\hline \multicolumn{3}{|l|}{ Días de hospitalización } \\
\hline Promedio (DE) & \multicolumn{2}{|c|}{$5,5(6,1)$} \\
\hline \multicolumn{3}{|l|}{ Gravedad } \\
\hline Mediana-Grave & 22 & (20) \\
\hline Leve & 88 & (80) \\
\hline \multicolumn{3}{|l|}{ Co-infección viral respiratoria } \\
\hline Sí & 41 & $(37,3)$ \\
\hline No & 69 & $(62,7)$ \\
\hline \multicolumn{3}{|l|}{ Diagnóstico de egreso } \\
\hline IRA alta & 24 & $(21,8)$ \\
\hline IRA baja & 80 & $(72,7)$ \\
\hline Asma & 6 & $(5,5)$ \\
\hline
\end{tabular}

Tabla 2. Distribución de los virus respiratorios detectados en 110 niños hospitalizados por infección respiratoria aguda. Santiago, junio-agosto 2010

\begin{tabular}{|lcc|}
\hline & $\mathbf{n}$ & $\%$ \\
Virus respiratorio sincicial & 87 & $(79,1)$ \\
VRS (detección única) & 47 & $(42,7)$ \\
VRS + bocavirus & 10 & $(9,1)$ \\
VRS + MPV & 9 & $(8,2)$ \\
VRS + influenza B & 8 & $(7,3)$ \\
VRS + bocavirus + influenza B & 3 & $(2,7)$ \\
VRS + parainfluenza & 3 & $(2,7)$ \\
VRS + rinovirus & 3 & $(2,7)$ \\
VRS + influenza A & 2 & $(1,8)$ \\
VRS + influenza C & 1 & $(0,9)$ \\
VRS + rinovirus + ADV & 1 & $(0,9)$ \\
Influenza A & 6 & $(5,5)$ \\
Influenza B & 5 & $(4,5)$ \\
Influenza B + rinovirus & 1 & $(0,9)$ \\
Adenovirus & 2 & $(1,8)$ \\
Bocavirus & 6 & $(5,5)$ \\
Metapneumovirus & 3 & $(2,7)$ \\
\hline Parainfluenza & 4 & $(3,6)$ \\
Rinovirus & 2 & $(1,8)$ \\
\hline Total & 110 & \\
\hline MPV: metapneumovirus; ADV: adenovirus. & & \\
\hline
\end{tabular}

Tabla 3. Descripción clínica de 110 niños con co-infección respiratoria viral o infección respiratoria viral única hospitalizados por infección respiratoria aguda (IRA). Santiago, junio-agosto 2010

\begin{tabular}{|c|c|c|c|c|}
\hline & \multicolumn{2}{|c|}{ Co-infección viral (41) } & \multicolumn{2}{|c|}{$\begin{array}{c}\text { Infección viral única } \\
(69)\end{array}$} \\
\hline & $\mathrm{n}$ & $\%$ & $n$ & $\%$ \\
\hline \multicolumn{5}{|l|}{ Sexo } \\
\hline Masculino & 20 & $(48,8)$ & 33 & $(47,8)$ \\
\hline \multicolumn{5}{|l|}{ Diagnóstico de egreso } \\
\hline IRA Alta & 9 & (22) & 15 & $(21,7)$ \\
\hline IRA baja & 29 & $(70,7)$ & 51 & $(73,9)$ \\
\hline Asma & 3 & $(7,3)$ & 3 & $(4,3)$ \\
\hline \multicolumn{5}{|l|}{ Gravedad clínica } \\
\hline Moderado a Grave & 6 & $(14,6)$ & 16 & $(23,2)$ \\
\hline Leve & 35 & $(85,4)$ & 53 & $(76,8)$ \\
\hline \multicolumn{5}{|l|}{ Días de hospitalización } \\
\hline Promedio (DE) & 4,3 & $(2,8)$ & 6,3 & $(7,4)$ \\
\hline \multicolumn{5}{|l|}{ Edad } \\
\hline Edad promedio en meses (DE) & 37,7 & $(47)$ & 27,2 & $(36,4)$ \\
\hline \multicolumn{5}{|l|}{ Distribución según edad } \\
\hline$<12$ meses & \multicolumn{2}{|c|}{11} & \multicolumn{2}{|c|}{26} \\
\hline $13-23$ meses & \multicolumn{2}{|c|}{9} & \multicolumn{2}{|c|}{20} \\
\hline 2-5 años & \multicolumn{2}{|c|}{14} & \multicolumn{2}{|c|}{15} \\
\hline$>5$ años & \multicolumn{2}{|c|}{7} & \multicolumn{2}{|c|}{8} \\
\hline \multicolumn{5}{|l|}{ Días de oxígenoterapia } \\
\hline Promedio (DE) & 2,73 & $(2,79)$ & 4,29 & $(6,30)$ \\
\hline
\end{tabular}

Tabla 4. Descripción clínica de 110 niños hospitalizados por infección respiratoria aguda según gravedad de la evolución clínica. Santiago, junio-agosto 2010

\section{Curso clínico}

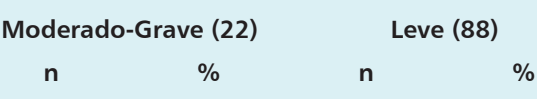

Sexo

$\begin{array}{lcccc}\text { Masculino } & 14 & (63,6) & 39 & (44,3) \\ \text { Edad } & & & & \\ \quad \text { Edad promedio en meses (DE) } & 28,56 & (37,92) & 31,76 & (41,63)\end{array}$

Diagnóstico de egreso

$\begin{array}{lcccc}\text { IRA Alta } & 0 & (0) & 24 & (27,3) \\ \text { IRA baja } & 19 & (86,4) & 61 & (69,3) \\ \text { Asma } & 3 & (13,6) & 3 & (3,4)\end{array}$

Co-infección viral respiratoria

$\begin{array}{lcccc}\mathrm{Si} & 6 & (27,3) & 35 & (39,8)\end{array}$

$\begin{array}{llll}16 & (72,7) & 53 & (60,2)\end{array}$

Días de hospitalización

Promedio (DE)

9,5

$(4,86)$

4,6

$(6,09)$

Días de oxigenoterapia

Promedio (DE)

8,57

$(4,48)$

2,55

$(4,81)$

${ }^{*} p<0,05$ 
al ingreso $(21 / 22,95 \%$ versus $46 / 88,52 \%$; $p<0,05)$. No hubo diferencia significativa entre la presencia de coinfección respiratoria viral y gravedad clínica, así como tampoco en el promedio de edad de ambos grupos (Tabla 4). Sin embargo, se observó que la evolución grave fue más frecuente en los pacientes bajo 24 meses de edad (15/22), con casi un tercio de los casos observados en niños bajo 6 meses de edad (8/22). Cabe destacar que en $100 \%$ de los pacientes del grupo MG se detectó VRS como virus infectante.

\section{Discusión}

En el presente estudio se demostró co-infección respiratoria viral en $37 \%$ de los niños hospitalizados por IRA que tuvieron detección molecular de algún virus respiratorio. La presencia de co-infección no se relacionó con una mayor gravedad en la evolución clínica. El virus que se detectó con mayor frecuencia en los pacientes con y sin co-infección fue el VRS.

Múltiples estudios sugieren que la co-infección viral respiratoria en niños es responsable de infecciones respiratorias de curso más grave $\mathrm{e}^{2-6-11,12}$; por el contrario, otros datos publicados reportan que la co-infección respiratoria viral en niños cursando IRA no se asocia con una evolución más grave $\mathrm{e}^{13-17-20-23}$. En nuestro estudio, la presencia de co-infección no fue determinante en el requerimiento de $\mathrm{FIO}_{2} \geq 0,5$, ni mayor necesidad de asistencia ventilatoria o en el ingreso a unidades de cuidado intensivo así como tampoco estadías hospitalarias más prolongadas.

Escobar y cols. ${ }^{14}$, describieron en nuestro país, en el año 1988, co-infección viral en 16\% (13/81) de un grupo de niños utilizando inmunofluorescencia, serología y aislamiento viral como métodos diagnósticos. La frecuencia de co-infección respiratoria viral encontrada en nuestro estudio (37\%) es concordante con lo publicado en la literatura médica internacional, donde la frecuencia de coinfección varía entre 17 y $35 \%$, dependiendo del número de pruebas diagnósticas y de la metodología utilizada para detectar una etiología viral 1-5-7-17-20,23 $^{\text {La detección }}$ múltiple de virus respiratorios aumenta al utilizar pruebas de diagnóstico molecular, demostrándose que el uso de la RPC ha mejorado sustancialmente la detección de patógenos respiratorios ${ }^{1-5}$. Frobert y cols. ${ }^{17}$, utilizando un método de diagnóstico molecular capaz de detectar 17 virus respiratorios, describieron $35 \%$ de co-infección en 57 niños, porcentaje similar al observado en el presente estudio y también a lo demostrado por Franz y cols. ${ }^{23}$, en su serie con 34\% de co-infección viral en 300 niños cursando IRA. En ambos estudios se utilizó RPC como método de diagnóstico.

Se ha descrito que la co-infección viral respiratoria ocurre más frecuentemente en lactantes bajo 1 año de edad $^{8-11-21}$. Sin embargo, en nuestro estudio el promedio de edad de los co-infectados fue mayor (37 meses) que lo descrito en la literatura científica.

Virus respiratorio sincicial es el virus detectado con mayor frecuencia en episodios de IRA, tanto en los pacientes co-infectados como en los con infección respiratoria viral única ${ }^{1,2,14,17,21}$. Drews y cols. ${ }^{11}$, plantean que la presencia de VRS en la mayoría de las co-infecciones se debería a que este virus podría facilitar la infección por un segundo virus respiratorio.

Se detectó VRS como agente causal en todos los niños que cursaron una IRA grave, lo que concuerda con lo descrito por García y cols. ${ }^{24}$, quienes comunicaron que lactantes sanos que cursaron con bronquiolitis por VRS tenían un curso más grave que aquellos con bronquiolitis no VRS, especialmente bajo 2 años de edad. Marguet y cols. ${ }^{22}$ describieron que el VRS por sí mismo puede ser una causa de IRA de curso grave, ya que al igual que lo descrito en nuestra serie, los pacientes con VRS co-infectados con otro(s) virus no presentaron un curso clínico más grave (no requirieron más apoyo ventilatorio) que aquellos infectados con VRS como agente único.

El presente estudio tiene varias limitaciones. Sólo se incluyeron pacientes hospitalizados y con los resultados obtenidos no se puede descartar que la co-infección sea un factor de riesgo para hospitalización. Cilia y cols. $^{8}$, demostraron que los niños con co-infección viral requieren hospitalización con mayor frecuencia. No es posible realizar alguna hipótesis acerca de los pacientes ambulatorios a partir de este estudio. Se utilizó sólo un método de diagnóstico molecular, aunque se sabe que la detección de co-infección mejora al aumentar el número de métodos, sean o no moleculares ${ }^{11}$.

Otra limitación del estudio es que se llevó a cabo sólo durante los meses de otoño-invierno, cuando se presenta la mayor frecuencia de enfermedades respiratorias virales en niños, y donde el virus predominante es el VRS, dificultando así el estudio y potencial importancia de la co-infección por otros virus respiratorios que se presentan en otras épocas del año.

No se puede excluir que entre los pacientes sintomáticos en los que se detecta más de un virus, se trate de infecciones respiratorias independientes, pero cercanas en el tiempo ${ }^{11-17}$; la presencia de múltiples virus puede ser producto de infecciones sucesivas previas que son detectadas por la técnica molecular utilizada, es decir, podría tratarse de persistencia de genoma, pero no necesariamente infección viral activa. En el futuro, con técnicas moleculares cuantitativas se podría llegar a un diagnóstico más certero ${ }^{17}$, pudiéndose demostrar no sólo la presencia del virus sino también su actividad o replicación mediante la medición de la carga viral. Franz y cols. ${ }^{23}$ determinaron la carga viral y bacteriana de patógenos respiratorios en muestras de aspirado nasofaríngeo en población pediátrica 
mediante RPC, concluyendo que tanto la co-infección viral como la carga viral contribuyen a la gravedad de la infección.

A través de este estudio se demuestra la existencia de co-infección respiratoria viral en aproximadamente $1 / 3$ de los niños que cursan IRA alta o baja, de curso leve-moderado y grave, y que son internados, con una prevalencia levemente superior a lo descrito previamente.

El uso de RPC permite aumentar la detección de virus respiratorios en muestras de aspirado nasofaríngeo en niños que cursan una IRA, pudiendo mejorar el diagnóstico etiológico en un mayor número de casos y permitiendo además la detección de co-infección viral con mayor frecuencia, transformándose así en una herramienta diagnóstica rápida, y accesible. La co-infección es aparentemente un fenómeno frecuente, cuya significación requiere de más estudios.

En conclusión mediante el uso de técnicas de diagnóstico molecular para detectar diferentes virus respiratorios se demostró la presencia de co-infección viral en un alto porcentaje de niños con IRA. No fue posible demostrar que la presencia de co-infección viral se relacione con una evolución clínica más grave en niños hospitalizados.

Agradecimientos: Al personal de enfermería del Centro de Pacientes Críticos Pediátricos de Clínica Las Condes, que colaboró con rigurosidad en la toma y recolección de la muestra para la detección de virus respiratorios.

\section{Resumen}

Introducción: Los virus respiratorios son la principal causa de infección aguda del tracto respiratorio (IRA) en pediatría. Se ha descrito que la co-infección viral podría relacionarse con infecciones virales respiratorias de curso más grave. Objetivo: Describir la frecuencia de co-infección viral en niños hospitalizados por IRA y determinar si esta co-infección se relacionó con una evolución clínica más grave. Pacientes y Métodos: Estudio descriptivo, prospectivo, en pacientes pediátricos hospitalizados por IRA entre junio y agosto 2010, que tuvieron detección molecular de al menos un virus respiratorio en muestra nasofaríngea estudiada por RPC-microarreglo para 17 virus respiratorios. Resultados: Se incluyeron 110 de 147 pacientes con detección de $\geq 1$ virus respiratorio. Se detectó co-infección viral en 41/110 (37\%). En cuanto a evolución clínica, 22/110 niños (20\%) se clasificaron como evolución moderada a grave (MG) y 88/110 (80\%) se clasificaron como evolución leve (L). En el grupo MG se detectó co-infección viral respiratoria en 6/22 (27,3\%), mientras que en el grupo L se detectó co-infección en $35 / 88$ (39,8\%). No se encontró diferencia significativa en relación a la presencia de co-infección entre ambos grupos $(\mathrm{p}=0,33)$. Conclusión: Se demostró la presencia de co-infección viral en un alto porcentaje de niños con IRA. No fue posible demostrar que la presencia de coinfección viral tenga relación con una evolución clínica más grave en estos niños hospitalizados.

\section{Referencias}

1.- Bonzel L, Tenenbaum T, Schroten H, Schildgen O, Schweitzer-Krantz S, Adams $\mathrm{O}$. Frequent detection of viral coinfection in children hospitalized with acute respiratory tract infection using a real-time polymerase chain reaction. Pediatr Infect Dis J 2008; 27 : 589-94.

2.- Noyola D E, Rodríguez-Moreno G, SánchezAlvarado J, Martínez-Wagner R, Ochoa-Zavala J R. Viral etiology of lower respiratory tract infections in hospitalized children in Mexico. Pediatr Infect Dis J 2004; 23: 118-23.

3.- Hustedt J W, Vázquez M. The changing face of pediatric respiratory tract infections: how human metapneumovirus and human bocavirus fit into the overall etiology of respiratory tract infections in young children. Yale J Biol Med 2010; 83: 193-200.

4.- $\quad$ Leung T F, To M Y, Yeung A C, Wong Y S, Wong G W, Chan P K. Multiplex molecular detection of respiratory pathogens in children with asthma exacerbation. Chest 2010; 137: 348-54.

5.- van der Zalm M M, van Ewijk B E, Wilbrink B,
Uiterwaal C S, Wolfs T F, van der Ent C K. Respiratory pathogens in children with and without respiratory symptoms. J Pediatr 2009; 154: 396-400, e1.

6.- Richard N, Komurian-Pradel F, Javouhey E, Perret M, Rajoharison A, Bagnaud A, et al. The impact of dual viral infection in infants admitted to a pediatric intensive care unit associated with severe bronchiolitis. Pediatr Infect Dis J 2008; 27: 213-7.

7.- Aberle J H, Aberle S W, Pracher E, Hutter H P, Kundi M, Popow-Kraupp T. Single versus dual respiratory virus infections in hospitalized infants: impact on clinical course of disease and interferon-gamma response. Pediatr Infect Dis J 2005; 24: 605-10.

8.- Cilla G, Onate E, Pérez-Yarza EG, Montes M, Vicente D, Pérez-Trallero E. Viruses in community-acquired pneumonia in children aged less than 3 years old: High rate of viral coinfection. J Med Virol 2008; 80: 1843-9.

9.- Suryadevara M, Cummings E, Bonville C A, Bartholoma N, Riddell S, Kiska D, et al. Viral etiology of acute febrile respiratory illnesses in hospitalized children younger than 24 months. Clin Pediatr (Phila) 2011; 50: 513-7.
10.- Chiu C Y, Urisman A, Greenhow T L, Rouskin S, Yagi S, Schnurr D, et al. Utility of DNA microarrays for detection of viruses in acute respiratory tract infections in children. J Pediatr 2008; 153: 76-83.

11.- Drews A L, Atmar R L, Glezen W P, Baxter B D, Piedra P A, Greenberg S B. Dual respiratory virus infections. Clin Infect Dis 1997; 25: 1421-9.

12.- Greensill J, McNamara P S, Dove W, Flanagan B, Smyth R L, Hart C A. Human metapneumovirus in severe respiratory syncytial virus bronchiolitis. Emerg Infect Dis 2003; 9: 372-5.

13.- Mansbach J M, Camargo C A, Jr. Respiratory viruses in bronchiolitis and their link to recurrent wheezing and asthma. Clin Lab Med 2009; 29: 741-55.

14.- Escobar A M, Martínez F, Ceruti E, Díaz A, Vicente M, Farías P, et al. Etiology of acute lower respiratory tract infections in hospitalized infants: virologic studies. Rev Chil Pediatr 1988; 59: 349-53.

15.- Tager F M, Zolezzi R P, Folatre B I, Navarrete $\mathrm{C}$ M, Rojas P J. Respiratory virus infections in children with acute lymphoblastic leukemia and 
febrile neutropenia: a prospective study. Rev Chil Infectol 2006; 23: 118-23.

16.- Palomino M A, Larrañaga C, Villagra E, Camacho J, Avendaño LF. Adenovirus and respiratory syncytial virus-adenovirus mixed acute lower respiratory infections in Chilean infants. Pediatr Infect Dis J 2004; 23(4): 337-41.

17.- Frobert E, Escuret V, Javouhey E, Casalegno J S, Bouscambert-Duchamp M, Moulinier C, et al. Respiratory viruses in children admitted to hospital intensive care units: evaluating the CLART(R) Pneumovir DNA array. J Med Virol 2011; 83: 150-5.

18.- Falchi A, Turbelin C, Andreoletti L, Arena C, Blanchon T, Bonmarin I, et al. Nationwide surveillance of 18 respiratory viruses in patients with influenza-like illnesses: A pilot feasibility study in the French Sentinel Network. J Med
Virol 2011; 83: 1451-7.

19.- Renois F, Talmud D, Huguenin A, Moutte L, Strady C, Cousson J, et al. Rapid detection of respiratory tract viral infections and coinfections in patients with influenza-like illnesses by use of reverse transcription-PCR DNA microarray systems. J Clin Microbiol 2010; 48: 3836-42.

20.- Fairchok M P, Martin E T, Chambers S, Kuypers J, Behrens M, Braun L E, et al. Epidemiology of viral respiratory tract infections in a prospective cohort of infants and toddlers attending daycare. J Clin Virol 2010; 49: $16-20$.

21.- García-García M L, Calvo C, Falcon A, Pozo F, Pérez-Breña P, De Cea J M, et al. Role of emerging respiratory viruses in children with severe acute wheezing. Pediatr Pulmonol 2010;
45: 585-91.

22.- Marguet C, Lubrano M, Gueudin M, Le Roux P, Deschildre A, Forget C, et al. In very young infants severity of acute bronchiolitis depends on carried viruses. PLoS One 2009; 4: e4596.

23.- Franz A, Adams O, Willems R, Bonzel L, Neuhausen N, Schweizer-Krantz S, et al. Correlation of viral load of respiratory pathogens and co-infections with disease severity in children hospitalized for lower respiratory tract infection. J Clin Virol 2010; 48: 239-45.

24.- García C G, Bhore R, Soriano-Fallas A, Trost $\mathrm{M}$, Chason R, Ramilo O, et al. Risk factors in children hospitalized with RSV bronchiolitis versus non-RSV bronchiolitis. Pediatrics 2010; 126: e1453-60. 